Vol.: 5 Issue: 2 Date: 31.12.2021 Received: 19.12.2021 Accepted: 29.12.2021 Final Version: 31.12.2021

ISVOS Journal, 2021, 5(2): 230-240 - https://doi.org/10.47897/bilmes.1038500

\title{
The Effects of Space Radiation on Small Satellites-General Structure of Cubesat and Internet of Space Things
}

\author{
Merve ALTUNAY ${ }^{\mathrm{a}, 1}$, Mustafa Alper AKKAŞa ${ }^{\mathrm{a}}$ Özge GÖYa \\ ${ }^{a}$ Bolu Abant İzzet Baysal Üniversitesi, Bilgisayar Mühendisliği Bölümü, Bolu, Türkiye \\ ORCID ID: 0000-0002-5227-7699 \\ ORCID ID: 0000-0003-0185-0464 \\ ORCID ID: 0000-0003-0259-1652
}

\begin{abstract}
Small satellites have started to be produced as a solution to the volume, weight and cost problems of traditional satellites. CubeSat as a small nano satellite whose production is gaining speed today, has contributed to research in space and satellite with the Internet of Things. CubeSat networks that can communicate each other in space are created with the development of the Internet of Things. The performance of satellites is attempted to be maximized with small satellites. Small electronic components of these satellites increase the sensitivity to space radiation. At the same time, the performance of the satellite is affected. More durable materials are being developed to minimize these impacts. In addition, satellites are tested for their durability by irradiating the satellite to be sent with close amounts of space radiation before it is sent into space. Signals that are important in satellite communication are affected by atmospheric conditions. In this context, the effect of the ionosphere which is the layer of the atmosphere on signals is mentioned. A compilation article about CubeSat networks that bring the concept of the Internet of Space Things to the fore, the effects of space radiation on small satellites, the materials that can be used on small satellites to reduce this effect and the radiation tests conducted has been written to address the lack of local resources.
\end{abstract}

Keywords: "Cubesat, Graphene, Small Satellite, Nanocomposite, Radiation Test, Space Radiation"

\section{Giriş}

Nanoteknolojinin ilerlemesi kullandığımız birçok teknolojik aletin de küçülmesini sağlamıştır. Bu teknolojinin önemini, 1959 yılında Nobel ödüllü fizikçi Richard Feynman "Altta Çok Yer Var” adlı konuşmasında vurgulamıştır. Bu konuşmasında nano boyutlarda üretim yapılmasının teknolojide ilerleme kaydedileceğini de söylemiştir. Bu ilerleme uydu ve uzay gelişmelerini etkilemiştir [1]. Geleneksel uydular önceleri çok büyük boyutlara sahipken günümüzde uydu teknolojilerinin gelişmesiyle birlikte bu uyduların boyutları küçültülmüştür. Bu küçük uyduların en çok tercih edildiği nanoteknolojiyle donatılmış olan CubeSat uydularının üretimi hız kazanmıştır. Bu uydular sayesinde uzay araştırmaları daha hızlı ve daha kolay olabilmektedir. İlk başlarda eğitim alanında araştırma yapmak için üretilse de şu an uzayda daha az maliyetli test yapma olanağı ve uyduya yerleştirilen güneş hücrelerinden enerji sağlama gibi çok farklı alanlarda kullanılabilmektedir. Ayrıca uzayda ağ oluşturarak Dünya'daki yer istasyonu ile direkt olarak bağlantı kurulabilmektedir.

CubeSat gibi küçük uyduların hem ülkemizde hem de dünyada daha az maliyetli olmasının da etkisiyle üretimi artmıştır. Hint Lisesi öğrenci ekibi tarafından tasarlanan KalamSat, 64 gr ağırlığında, karbon fiberden yapılan dünyanın en küçük uydusudur. Bu uydunun üzerinde yeni bir bilgisayar ve dünyanın magnetosferini ölçecek sekiz alıcı bulunmaktadır. Haziran 2017'de bir NASA tesisi tarafından uzaya firlatılmıştır. Eylül 2011'de ESA (European Space Agency) tarafından yürütülen bir proje kapsamında Clyde Space Ltd, Mars Space Ltd ve Southampton Üniversitesi tarafından CubeSat'ın ömrünü 600 km'lik bir yörüngede iki katına çıkarabilecek bir Pulsed Plasma Thruster tasarlanmıştır [2]. Dünyada küçük uydu alanındaki çalışmalara paralel olarak ülkemizde küp uydu şeklinde TÜRKSAT için geliştirilmiş olan TÜRKSAT-3USAT ile haberleşme uydularında ilerleme kaydedilmiştir [3]. Ayrıca uzaya başarı ile gönderilen ilk küp uydumuz İTÜpSAT1, İTÜ Uzay Mühendisliği Bölümü’nde yapılmıştır [4].

Uzay ortamındaki olumsuz koşullara dayanıkıı bir uydu üretmek yapılan çalışmaların zorlayıcı kısmı olmaktadır. CubeSat'ların uzay koşullarına karşı daha hassas olması nedeniyle üretimi sırasında ek olarak olumsuzlukları en aza indirmek için çalışmalar yapıldığı görülmektedir. Bunlardan birisi ekranlama yöntemidir. Bu yöntemde ekranlama etkinliği için elektrik iletkenliği yüksek olan grafen kullanılmaktadır. Bu nedenle uydunun daha dayanıklı olabilmesi için grafen temelli malzemeler seçilmektedir. Ayrıca uzaya gönderilmeden önce uydu üzerinde belirli testler yapmak son derece önemlidir. 


\section{Uydular ve Yörüngeleri}

Uydular dünyanın etrafında yörünge üzerinde birbirine çarpışmadan dönmektedirler. Dünya’ya olan uzaklıklarına ve kullanım amaçlarına göre farklı yörünge tiplerine sahiptirler [5].

\subsection{Dünya'ya Uzaklıklarına Göre Uydu Yörüngeleri}

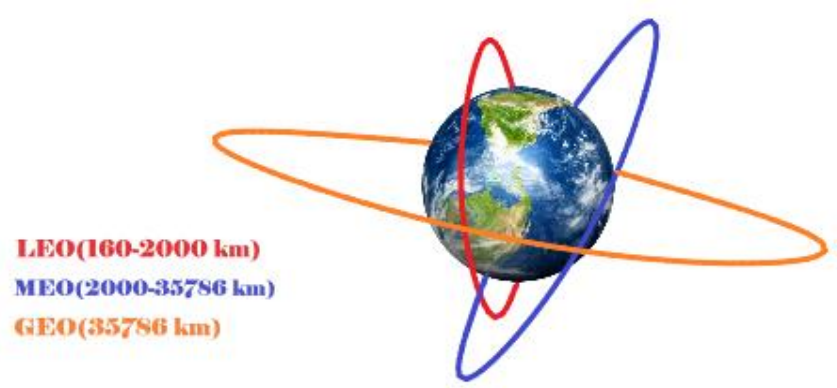

Şekil 1. Uydu Yörüngeleri

Tablo 1'de görüldüğü üzere uydu yörüngelerinden LEO, Dünya'ya yakın olduğundan görüş açısı en az olandır. Görüş açısını arttırmak için diğer yörüngelere göre daha fazla uyduya ihtiyaç duyulmaktadır. Bunun yanı sıra bu uyduların yörüngede kalabilmesi için gereken hız artmaktadır. Buna bağlı olarak da diğer yörüngelere göre daha fazla enerji harcanmaktadır. Bu nedenle Dünyaya yaklaştıkça uyduların ticari ömürleri azalmaktadır.

Uydu haberleşmesinde gönderilen sinyallerin uyduya ulaşma süresi mesafe uzamasına bağlı olarak artmaktadır. Bundan dolayı GEO yörüngesinin gecikme süresi diğerlerine göre daha fazladır. Uydular yörüngesine yerleştirildikten sonra uydunun konumunun bozulması yerçekimi kuvvetindeki bir değişikliğe, az bir oranda da olsa atmosferik sürtünme ve radyasyon etkileri gibi dış etkenlere bağlidir [6].

Tablo 1. Uydu yörüngeleri özellikleri [6]

\begin{tabular}{|c|c|c|c|c|c|}
\hline $\begin{array}{l}\text { Uydu } \\
\text { Yörüngeleri/ }\end{array}$ & $\begin{array}{c}\text { Dünya'ya Olan } \\
\text { Uzaklığı }\end{array}$ & $\begin{array}{l}\text { Görüş Açısı } \\
\text { için Uydu } \\
\text { Miktarı }\end{array}$ & Gecikme Süresi & $\begin{array}{l}\text { Uydu Ticari } \\
\text { Ömürleri }\end{array}$ & Kullanım Alanı \\
\hline Özellikleri & & & & & \\
\hline LEO & $160-2000 \mathrm{~km}$ & $\begin{array}{l}40 \text { ve } \\
\text { üzeri }\end{array}$ & 0.05 saniye & 4-7 y1l & $\begin{array}{l}\text { Yer gözlem uyduları ve } \\
\text { uydu telefon sistemleri }\end{array}$ \\
\hline MEO & $2000-35786 \mathrm{~km}$ & $10-15$ & 0.10 saniye & $15 \mathrm{y} 1 \mathrm{l}$ & $\begin{array}{c}\text { Yer gözlem ve GPS } \\
\text { uyduları }\end{array}$ \\
\hline GEO & $35786 \mathrm{~km}$ & $3-4$ & 0.25 saniye & $10-15$ y1l & $\begin{array}{c}\text { Televizyon ve radyo } \\
\text { yayıncılığı, hava durumu } \\
\text { izleme, GPS, VSAT, SCPC } \\
\text { vb. sistem uyduları }\end{array}$ \\
\hline
\end{tabular}




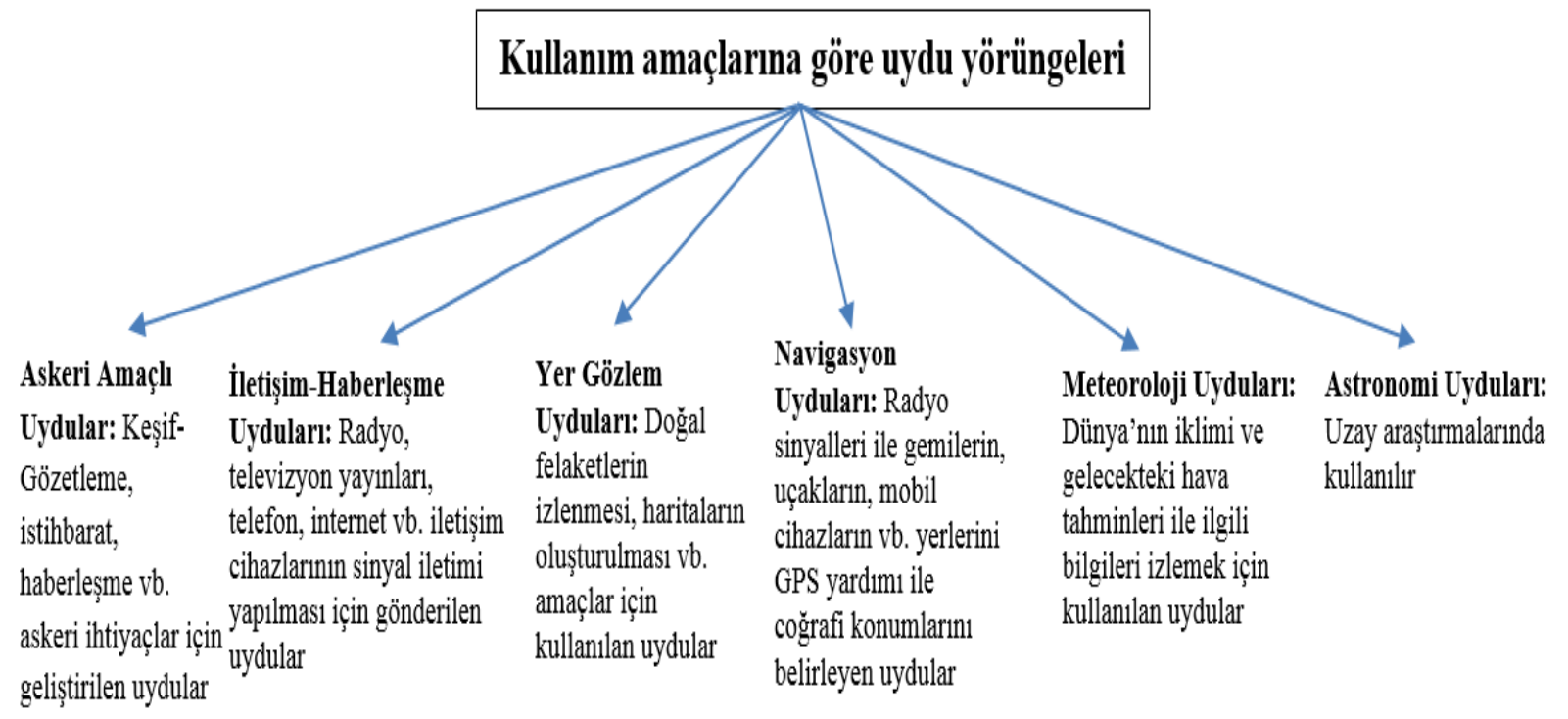

Şekil 2. Kullanım Amaçlarına Göre Uydu Yörüngeleri [5]

\section{Uzay Ortamında Uydulara Etkiyen Olumsuz Koşullar}

Küçük uyduların uzay araştırma alanındaki uygulamalar için kullanımındaki artışla uyduları etkileyen olumsuz nedenlere yönelik birçok çalışma yapılmaktadır. Bir uyduyu uzaya gönderdikten sonra dayanıklılığını korumak, uzay ortamının zorlayıcı koşullarından dolayı kolay değildir. Uzayda havanın bulunmaması, sıcaklık değerleri, radyasyon vb. etkenler uydular için ciddi boyutlarda tehdit oluştururlar. Küçük uydular küçük elektronik malzemelere sahip olması ile bu etkenlerden diğer uydulara göre daha fazla etkilendiği gözlemlenmiştir [7].

Elektromanyetik dalgalarının zararlı etkilerinin azaltılması için ekranlama sıklıkla kullanılan yöntemlerden biridir. Ekranlamanın ölçüsü olan ekranlama etkinliğinin yüksek olması uydu içerisinde kullanılan elektronik malzemenin elektrik iletkenliğinin iyi olmasına bağlıdır. İki boyutlu bir karbon dizilimi ve atomları altıgen şeklinde olan grafen, bilinen en dayanıklı, hafif ve en süper iletkenlerden biridir. Bu üstün özelliklerinden dolayı küçük uydularda grafen malzemesinin kullanılması öngörülmektedir. Ayrıca günümüzde gelişmiş ülkelerdeki endüstriyel firmalar grafeni farklı alanlarda kullanabilmek üzere birçok araştırma yapmaktadır. Uzaydaki olumsuz koşulların küçük uydulardaki etkisini azaltmaya yönelik yapılan çalışmalardan biri de uyduların üzerinde yapılan radyasyon testleridir. Bu testlere ek olarak uydu güç sisteminin performansını artırmak için güneş hücreleri üzerine uzay kalifikasyon testleri de yapılmaktadır [8].

\subsection{Radyasyon ve Çeşitleri}

Radyasyona basitçe basitçe ortamda taşınan enerji diyebiliriz. Aynı zamanda birçok zararlı etkilerle sonuçlanan bir enerji olan radyasyon günlük hayat, uzay vb. hemen hemen her yerde karşımıza çıkmaktadır. Radyasyon çeşitleri iyonlaştırıcı ve iyonlaştırıcı olmayan şeklinde iki ana grupta incelenmektedir. İyonlaştırıcı radyasyon atomlardan elektron koparan radyasyon olarak tanımlanmaktadır. Genellikle kullandığımız teknolojik aletlerden yayılan elektromanyetik dalgalar da iyonlaştırıcı olmayan radyasyon türü olarak bilinmektedir. Bu iki grubun örnekleri Tablo 2'de verilmiştir [9].

\subsection{Uzay Radyasyonu ve Etkileri}

Uzay ortamında bulunan radyasyonun doğal kaynakları Van Allen radyasyon kuşağı, galaktik kozmik ışınlar ve güneş sisteminden kaynaklanan parçacık olaylarını içermektedir. Dünya'yı halka şeklinde saran radyasyon alanı olarak bilinen Van Allen radyasyon kuşakları 1958 yılında Dr. Van Allen tarafından Amerika'nın ilk uydusu olan Explorer 1 fırlatıldıktan sonra keşfedilmiştir. Galaktik kozmik ışınlar güneş sisteminin dışından Gama ve X ışını radyasyonu ile birlikte gelen yıldız patlamalarından oluşan parçacıklardır. Güneş parçacıkları güneşten aralıklı olarak atılan protonlar, alfa parçacıkları ve ağır yüklü iyonları içermektedir. 
Tablo 2. İyonlaştırıcı olan ve iyonlaştırıcı olmayan radyasyon çeşitleri [9]

\begin{tabular}{|c|c|c|}
\hline & \multicolumn{2}{|c|}{ Radyasyon Çeşitleri } \\
\hline & İyonlaştırıcı Radyasyon & İyonlaştırıcı olmayan Radyasyon \\
\hline $\begin{array}{l}\text { Dalga } \\
\text { Tipi }\end{array}$ & $\begin{array}{ll}\text { - } & \text { Gama 1şınları } \\
\text { - } & \text { X 1şınları }\end{array}$ & $\begin{array}{ll}\text { - } & \text { Radyo dalgaları } \\
\text { - } & \text { Mikrodalgalar } \\
\text { - } & \text { Körünür 1şık } \\
\text { Kizlötesi, morötesi dalgalar }\end{array}$ \\
\hline $\begin{array}{l}\text { Parçacık } \\
\text { Tipi }\end{array}$ & $\begin{array}{ll}\text { - } & \text { Alfa 1şınları } \\
\text { - } & \text { Beta 1şınları } \\
\text { - } & \text { Hizlı elektronlar }\end{array}$ & - \\
\hline
\end{tabular}

Şekil 3'de görüldüğ̈̈ üzere Van Allen kuşakları çok yüksek enerjili elektron parçacıklarından oluşan iç ve dış radyasyon kuşaklarını içermektedir [9-10]. Bu kuşaklar manyetik alanın güçlü olmasından dolayı Dünya'nın etrafında kalabilmektedir. Ayrıca çok fazla rasyasyona sahip oldukları için uyduların ömrünü kısaltmaktadır.

Küçük uyduların geleneksel uydulardan daha hassas olması, radyasyondan daha çok etkilendiklerini göstermektedir. Bu etkilerin elektromanyetik ve parçacık radyasyonu olduğu görülmektedir. Elektromanyetik radyasyon mor ötesi, X ışınları ve gama ışınlarından oluşmaktadır. Mor ötesi ışıllar uydu yüzeylerindeki malzemelerin yapısının bozulmasına neden olmaktadır. Hatta malzeme özelliklerini bile değiştirebilmektedir. X ve gama ışınları da uyduların içerisindeki hassas elektroniklere zarar vermektedir. Parçacık radyasyonu elektromanyetik radyasyon vb. yüksek enerjili protonlar, mor ötesi ışınlar ile uydu yüzeylerine etki etmektedir. Radyasyon elektronik malzemelere önemli boyutlarda zarar verdiği için parça seçiminde elektromanyetik radyasyona karşı güçlendirilmiş veya yüksek güvenilirlikli malzemeler seçilmesi gerekmektedir [10].

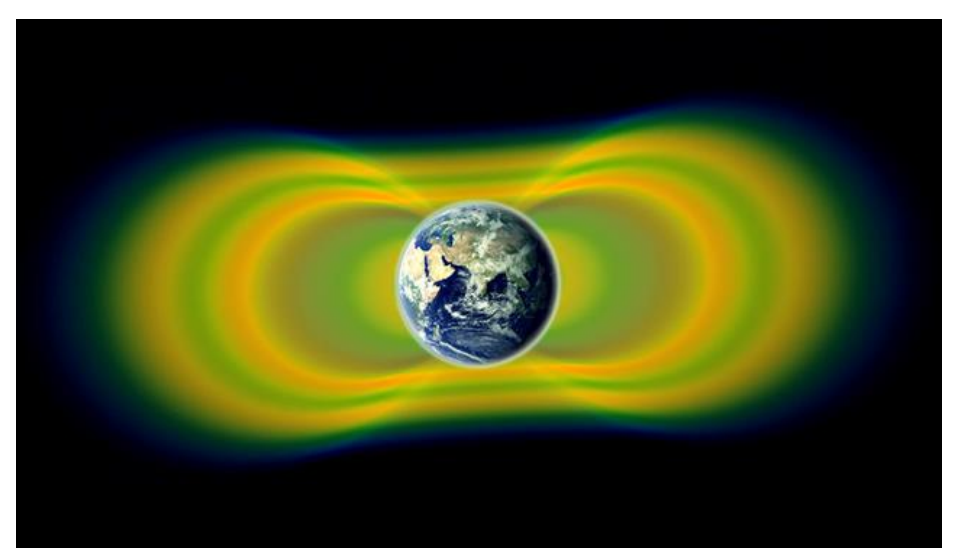

Şekil 3. Van Allen Radyasyon Kuşakları

Elektromanyetik dalgalar hem uzayda hem de madde içinde yayılmaktadır. Uzayda bu dalgalar ışık hızıyla gerçekleşmektedir. Kalkanlama teorisi elektromanyetik dalgaların zararlı etkilerinin azaltılması için ortaya atılmış̧ır. Bir elektromanyetik dalga küçük bir uydunun yüzeyine çarptı̆̆ı zaman bu dalganın etkisi üç şekilde azaltılabilir. Birincisi uydunun yüzeyine gelen dalganın yansımasıyla, ikincisi uydu içerisinde kullanılan malzemenin yansıyamayan dalgayı yutmasıyla ve üçüncüsü uydudaki boşluklardan sızan dalgalarla olan azalmalardır. Kalkanlamanın diğer bir adıyla ekranlamanın ölçüsü ekranlama etkinliği (SE, Shielding effectiveness) olarak kullanılmaktadır. SE, bir ekrana gelen manyetik alanın büyüklüğünün, ekrandan çıtıktan sonraki manyetik alanın büyüklüğ̈̈ne $\mathrm{dB}$ olarak oranıdır. Ekranlamanın iyi olabilmesi ekranlama etkinliğinin yüksek olmasına bağlıdır [11-12].

Ekranlama için kullanılan metal nanokompozit malzemelerde esnekliğin az, ağır olması, paslanması vb. olumsuzlukları görülmektedir. Ekranlama malzemelerinin olumsuzluklarından dolayı ekranlamada daha esnek, hafif, az maliyetli vb. olan ve elektromanyetik radyasyonu ekranlama amaçlı geliştirilen yeni nesil iletken nanokompozit malzemeler seçilmektedir. Bir elektromanyetik dalga küçük bir uydunun yüzeyine çarptığında bu dalganın etkisi uydu içerisinde kullanılan malzemenin bu dalgayı yutmasıyla azaltılabilmektedir. Bu malzemelerin elektromanyetik kalkanlama özelliğine sahip yani elektrik iletkenliği iyi ve manyetik geçirgenliği yüksek olmalıdır [12]. 
Kahramanmaraş Sütçü İmam Üniversitesi’nde yapılan bir çalışmada grafen maddesinin iyi bir elektromanyetik kalkanlama malzemesi olduğu görülmüştür. Bundan dolayı farklı oranlarda grafen katkılı odun-plastik (OPG) nanokompozitlerin OPG-1, OPG-2, OPG-3 ve OPG-4 gibi çeşitleri üretilmiştir. Bu nanokompozitlerin 8-9 GHz frekans aralığında elektromanyetik özelliği test edilmiştir. Bu test sonuçları Tablo 3 ’te verilmektedir [13].

Tablo 3'te görüldüğü üzere, OPG nanokompozitlerinin grafen oranı arttıkça yansıma güç parametre değerleri azalmaktadır. Bu durum yansıma kayıplarının artması demektir ve bu artışla birlikte ekranlama etkinliği de artacaktır. En yüksek emilme güç parametre değeri en düşük grafen oranı içeren OPG-1 nanokompozitinde görülmektedir. En düşük emilme güç parametre değeri ise en yüksek grafen oranı içeren OPG-4 nanokompozitinde görülmektedir. . Bu durumda yansıma güç parametre ve emilme güç parametre değerleri azaldıkça toplam elektromanyetik ekranlama etkinliği değeri artacağından nanokompozitler içerisinde en yüksek ekranlama performansı OPG-4 nanokompozitinde görülecektir.

Tablo 3. Grafen katkılı odun-plastik nanokompozitlerin elektromanyetik özellikleri [13]

\begin{tabular}{|c|c|c|c|c|}
\hline & \multicolumn{3}{|c|}{ Elektromanyetik Dĕgerler } \\
\hline & Grafen Oranı & $\begin{array}{c}\text { Yansıma Güc } \\
\text { Parametre Değerleri }\end{array}$ & $\begin{array}{c}\text { Toplam } \\
\text { Elektromanyetik } \\
\text { Ekranlama Etkinliği } \\
\text { Değerleri (dB) } \\
\text { Değerleri }\end{array}$ \\
\hline OPG-1 & $\% 0$ & $-0,2989$ & 0,6571 & 3,6463 \\
\hline OPG-2 & $\% 1,5$ & $-0,3395$ & 0,1565 & 16,1045 \\
\hline OPG-3 & $\% 3$ & $-0,3655$ & 0,1212 & 18,3277 \\
\hline OPG-4 & $\% 6$ & $-0,3961$ & 0,0692 & 23,1942 \\
\hline
\end{tabular}

Nanokompozitteki grafen oranı arttıkça ekranlama değeri de artarak OPG nanokompozitlerinin elektromanyetik radyasyonun önlenmesi için iyi bir ekranlama malzemesi olduğu görülmüştür. Hatta bu nanokompozitlerden en yüksek performans gösteren OPG-4 nanokompoziti olmuştur [13]. Bu konu üzerine yapılan diğer bir çalışmada nanokompozitin elektromanyetik ekranlama etkinliği 8.2-12.4 GHz frekans aralığında test edilerek nanokompozit modellerinin kalınlığının nasıl etki ettiği incelenmiştir. Değiştirilmemiş nanokompozitler elektromanyetik radyasyona karşı hassas olup grafen eklendikten sonra nanokompozitlerin toplam elektromanyetik ekranlama etkinliği önemli ölçüde arttığı görülmüştür. Daha kalın nanokompozit malzemelere gerek duymadan grafen sayesinde yüksek ekranlama etkinliği sağlanmıştır [14]. Yapılan bu çalışmalar doğrultusunda uydu içerisindeki malzemeler de iletken nanokompozit malzemelerden seçilerek elektromanyetik radyasyondan etkilenmesini azaltılabileceği sonucuna ulaşabiliriz.

Son yıllarda COTS (Commercial Off The Shelf) parçaların uzay projelerinde, düşük maliyetli ve teknolojik gelişmelere açık olduklarından dolayı daha fazla kullanıldığı görülmüştür. Ayrıca tasarımdaki parçaların değerleri ve tiplerinin uydunun performansını kötü etkilemeyecek şekilde seçilmekte ve radyasyona dayanıklılığını ölçmek için test çalışmaları yürütülmektedir [15].

\subsection{Uzay Radyasyonu Testleri}

Uydular uzaya gönderilmeden önce radyasyon testlerinden geçirilmesi uydu sistemlerinin güvenilirliğini artırmak veya gönderildikten sonra düzeltilemeyecek hatalar olmasını engellemek için çalışmalar yapılmakta ve geliştirilmektedir. Bu testlerin laboratuvar ortamlarında yapılmasının yanı sıra ülkelerin teknolojik gelişmelerine bağlı olarak uydular üzerinde uzaya gönderilerek test edilen uzay kalifikasyon testleri de yapılabilmektedir.

Ülkemizde Ağustos 2015'te Kalkınma Bakanlığı'ndan İMECE kapmasında alınan destek ile ODTÜ Saçılmalı Demet Hattı Projesi geliştirilmeye başlanmıştır. Uzay radyasyonuna karşı dayanıklılığı test etmek için Parçacık Radyasyonu Test Altyapısı kurulmuştur. Bu proje ile uyduların uzay ömürlerinin kısalmaması için uzay ortamına uygun testler yapılmaktadır. Ayrıca elektronik devrelerin uzay radyasyonuna karşı dayanıklılıkları da test edilmektedir. Uydularda kullanılacak malzemeler için ASELSAN'a ait mikrodalga modülleri test malzemesi olarak seçilmiştir. Bu kapsamda Havacılık ve Uzay Teknolojileri Genel Müdürlüğü ile ASELSAN ve Japonya Havacılık ve Uzay Keşif Ajansı arasında 2016'da iş birliği protokolü imzalanmıştır [16]. 
Tablo 4. Uyduların üretim yeri, kütlesi ve yük kapasitesi güç değerleri [17]

\begin{tabular}{|c|c|c|c|}
\hline \multirow{2}{*}{ Uydular } & \multicolumn{3}{|c|}{ Uyduların Kütle ve Güç Değerleri } \\
\hline & Üretici Firma/Ülke & Kütlesi & Yük Kapasitesi Güç Değerleri \\
\hline Demeter & CNES/Fransa & $50 \mathrm{~kg}$ & $70 \mathrm{~W}$ \\
\hline Iridium NEXT & Iridium Communications/ABD & $50 \mathrm{~kg}$ & $50 \mathrm{~W}$ \\
\hline Beosat & $\begin{array}{l}\text { Braunschweig Teknik } \\
\text { Üniversitesi/Almanya }\end{array}$ & $40 \mathrm{~kg}$ & $100 \mathrm{~W}$ \\
\hline TerraSAR-X & Astrium/Fransa & $1230 \mathrm{~kg}$ & $800 \mathrm{~W}$ \\
\hline CubeSTAR & Oslo Üniversitesi/Norveç & $2 \mathrm{~kg}$ & $4 \mathrm{~W}$ \\
\hline Kompsat-6 & KARI/Kore & $1750 \mathrm{~kg}$ & $2250 \mathrm{~W}$ \\
\hline EnviSat & Astrium/Fransa & $8211 \mathrm{~kg}$ & $6500 \mathrm{~W}$ \\
\hline UKube-1 & UKSA/İngiltere & $4 \mathrm{~kg}$ & $1.2 \mathrm{~W}$ \\
\hline
\end{tabular}

Uyduların güç sisteminin performansını artırmak radyasyondan daha az etkilenmelerini sağlayacaktır. Güç sisteminin enerji kaynağı da Şekil 4'de verilen güneş hücreleri olduğu için bu hücrelerin performansı ayrı olarak test edilmektedir. Güneş 1şınları güneş hücrelerinden yansımaya uğrayarak performans düşüklüğüne sebep olur. Bunun önüne geçebilmek için yansımaları engelleyen yüzeyde yansıma önleyici kaplamalar kullanılmaktadır. Aynı zamanda performansı artırmak için radyasyona dayanıklı çok eklemli güneş hücreleri de kullanılmaktadır.

Bir uydudan maksimum verim elde edebilmek için güç değerlerinin yüksek ve uydunun kütlesinin düşük olması istenmektedir. Tablo 4'de verilen uydu örneklerinde aynı kütleye sahip Demeter ve Iridium Next uydularının güç değerleri karşılaştııldığında Demeter uydusunun daha verimli olabileceğini söyleyebiliriz. EveSat uydusu $5 \mathrm{~kg}$ 'llk kütle ile $20 \mathrm{~W}$ güç, Iridium Next uydusu 50 kg'lık kütle ile $50 \mathrm{~W}$ güç sağlamıştır. EveSat'ın az kütleli olmasına rağmen kaç kat daha fazla verimli olduğu sonucuna varılabilir. Tablodaki küçük uyduları ele aldığımızda birbirine yakın kütleli olup fakat güç değeri diğerlerine göre fazla olan uydu EveSat uydusu olarak görülmektedir. Bu uydunun, enerji kaynağı güneş hücreleri olan güç performansındaki değerine bakıldığında uzay radyasyonundan az etkilenebileceği durumu ortaya çıkmaktadır.

Yapılan literatür çalışmalarında Amerika Uzay ve Havacılık Enstitüsü’nün belirlediği AIAA S-111A-2014 standartlarına göre, güneş hücrelerinin uzay ortamındaki radyasyondan etkilenmesini önleyecek uzay kalifikasyon testleri yapıldığı görülmüştür [18]. 


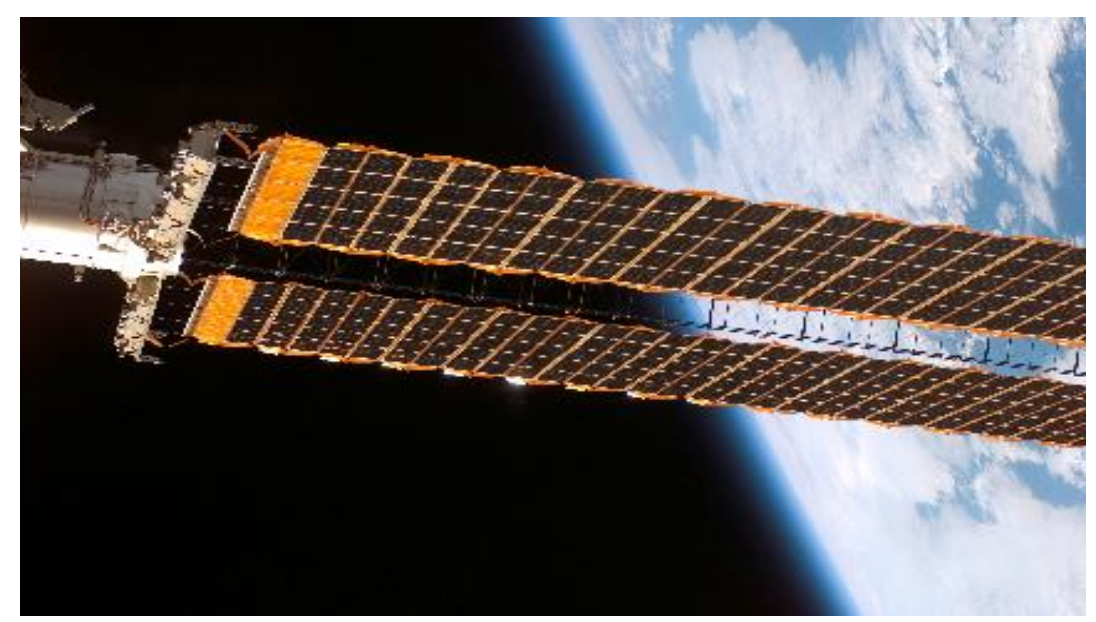

Şekil 4. Uydulardaki Güneş Hücreleri

\section{4. İyonosferin Uydu Sinyallerine Etkileri}

Termosfer tabakasının bir bölümü olan iyonosfer, yeryüzünden yaklaşık $60 \mathrm{~km}$ ile $1100 \mathrm{~km}$ arasında yüksekliktedir. Bu tabaka elektromanyetik dalgaların iletilmesi için gerekli olan iyonlardan oluşmaktadır. Ayrıca serbest elektron bulunduran iyonosfer radyo dalgarının yayılmasında bir etkiye sahiptir. Bu nedenle radyo iletişimindeki uyduların ilettiği sinyaller de iyonosfer tabakasından etkilenmektedir [19].

Sinyal uydudan çıktıktan sonra ilk olarak iyonosfer katmanı ile karşılaşmaktadır. Bu katmandan geçerken alıcıya ulaşmasında bir gecikmeye sebep olacak şekilde sinyalin hızı ve yönü değişebilmektedir. Sinyal üzerindeki etki Tablo 5'te verilen iyonosfer bölgelerinin her birinde farklılık göstermektedir. Bunun nedeni bölgelerdeki iyonlaşmanın aynı olmamasından kaynaklanmaktadır. Yüksekliğin artması iyonlaşmayı da artırmaktadır. Buna bağlı olarak F bölgesi en fazla iyonlaşmanın olduğu bölge olması sebebiyle uydu sinyalini daha çok etkilemektedir. Gündüz ve gece, iyonosferin farklı olması güneş yönüne göre değişmektedir. F bölgesi gündüz F1 ve F2 olarak ikiye bölünmekte ve geceleri ise tekrar birleşmektedir [20].

Tablo 5. İyonosfer bölgelerinin sinyal üzerindeki etkisi [20]

\begin{tabular}{|c|c|c|c|}
\hline & \multicolumn{3}{|c|}{ İyonosferin Bölgeleri } \\
\hline & D Bölgesi & E Bölgesi & F Bölgesi \\
\hline Bulunduğu Dilim & Yaklaşık 50-90 km & Yaklaşık 90-120 km & Yaklaşık 120-1000 km \\
\hline $\begin{array}{c}\text { Sinyal Üzerindeki } \\
\text { Etkisi }\end{array}$ & Hiçbir etkisi yok & $\begin{array}{l}\text { Hafif etkisi var ancak sinyalin } \\
\text { parlamasina neden olabilir }\end{array}$ & En çok etkisi olan bölge \\
\hline
\end{tabular}

Uydu haberleşmesinde gönderilen sinyalin alıcıya doğru bir şekilde ulaşabilmesi önemlidir. Ayrıca uyduların birbirleriyle olan iletişiminde performans yüksek olmalıdır. İyonosferden etkilenen GPS uydu sinyallerinin faz ve genliklerinde bozulmalar meydana gelmektedir. Bu nedenle de GPS verileri doğru bir şekilde alınamamaktadır. Bu bozulmalar sinyal parlaması olarak görülmektedir. Çok ciddi bir parlama yaşandığında GPS verisinden gelecek mesajları çözerken kod hatalarına ve GPS uydularındaki tahmin edilen aralıklarında bozulmasına neden olmaktadır [21]. 


\section{Cubesat}

Uzay ve uydu teknolojisindeki gelişmelerle birlikte bu alandaki uygulamaların artışı hız kazanmıştır. Bu uygulamalar üzerinde çalışan araştırmacılar düşük maliyet ve üretim sürecinin kısa olması nedeniyle küçük uydu sınıfına giren CubeSat'ları tercih etmektedir. Bu uydular ilk olarak 1999 yılında Stanford Üniversitesi'nde başlatılmıştır. 2003 yılında da ilk küp uydu Rusya'dan gönderilmiştir [22].

Cubesat'lar, geleneksel uyduların hacim, ağırlık ve maliyet sorunlarına çözüm olarak üretilmiştir. Tablo 6'da verilen CubeSat özelliklerine bakıldığında boyutları arttıkça kütlesinde de artış olduğu görülmektedir. Bu uyduların temel boyutları 10x10x10 cm olup kütlesi en fazla 1,33 kg'dır. Ağırlıklarının az olmasından dolayı fırlatma için gerekli yakıt miktarı da az olmaktadır. Bu da firlatma maliyetini düşürmektedir. Ayrıca çok fazla uydu gönderilerek maliyet en aza indirilmektedir. Aynı zamanda düşük dünya yörüngesinde (LEO) konumlandırılmaktadır. Bu yüzden genellikle düşük gecikme süresi gerektiren uzay araştırmalarında, uzaktan algılama ve görüntüleme sistemlerinde ve iletişim uygulamalarında kullanılmaktadır [22-23].

Tablo 6. Cubesat uyduları ve özellikleri [24]

\begin{tabular}{|c|c|c|c|c|c|c|c|}
\hline \multirow{2}{*}{ CUBESAT } & \multicolumn{7}{|c|}{ CUBESAT ÖZELLİKLERİ } \\
\hline & Ülke & Tip & İşletici & Boyut & Güç & Kütle & Yörünge \\
\hline SNAPS & $\mathrm{ABD}$ & Teknoloji & $\begin{array}{l}\text { Standford } \\
\text { Üniversitesi }\end{array}$ & $0.25 \mathrm{U}$ & Piller ve Güneş Pilleri & $0.5 \mathrm{~kg}$ & $\begin{array}{c}400 \mathrm{~km} \times 400 \\
\mathrm{~km}, 51.6^{\circ} \text { (tipik) }\end{array}$ \\
\hline AEROCUBE 6 & ABD & Teknoloji & Havacılık Şirketi & $0.5 \mathrm{U}$ & Piller ve Güneş Pilleri & $0.5 \mathrm{~kg}$ & $613 \mathrm{~km} \times 700 \mathrm{~km}, 97.9^{\circ}$ \\
\hline XI 4 & Japonya & Teknoloji & $\begin{array}{c}\text { Tokyo } \\
\text { Üniversitesi }\end{array}$ & $1 \mathrm{U}$ & Piller ve Güneş Pilleri & $1 \mathrm{~kg}$ & $\begin{array}{c}822 \mathrm{~km} \times 828 \\
\mathrm{~km}, 98.73^{\circ}\end{array}$ \\
\hline ANTELSAT & Uruguay & Teknoloji & $\begin{array}{l}\text { Republic } \\
\text { Üniversitesi }\end{array}$ & $2 \mathrm{U}$ & Piller ve Güneş Pilleri & $2 \mathrm{~kg}$ & $606 \mathrm{~km}$ x $621 \mathrm{~km}, 97.9^{\circ}$ \\
\hline CANX-2 & Kanada & Teknoloji & $\begin{array}{l}\text { Toronto } \\
\text { Üniversitesi }\end{array}$ & $3 \mathrm{U}$ & Piller ve Güneş Pilleri & $\begin{array}{l}3.5 \\
\mathrm{~kg}\end{array}$ & $\begin{array}{c}614 \mathrm{~km} \times 633 \\
\mathrm{~km}, 97.99^{\circ}\end{array}$ \\
\hline EcAMSAT & $\mathrm{ABD}$ & $\begin{array}{l}\text { Yaşam } \\
\text { Bilimleri }\end{array}$ & $\begin{array}{c}\text { Standford } \\
\text { Üniversitesi }\end{array}$ & $6 \mathrm{U}$ & Piller ve Güneş Pilleri & $\begin{array}{c}10.4 \\
\mathrm{~kg}\end{array}$ & $\begin{array}{c}399 \mathrm{~km} \times 407 \\
\mathrm{~km}, 51.64^{\circ}\end{array}$ \\
\hline $\begin{array}{c}\text { ALTAIR } \\
\text { PATHFINDER }\end{array}$ & $\mathrm{ABD}$ & Teknoloji & $\begin{array}{l}\text { Millennium Uzay } \\
\text { Sistemleri }\end{array}$ & $1 \times 6 \mathrm{U}$ & $\begin{array}{l}4 \text { Konuşlandırılabilir } \\
\text { Güneş Dizileri, Piller } \\
\text { ve Güneş Pilleri }\end{array}$ & $4 \mathrm{~kg}$ & $\begin{array}{c}401 \mathrm{~km} \times 404 \\
\mathrm{~km}, 51.64^{\circ}\end{array}$ \\
\hline $\begin{array}{l}\text { AOXIANG } \\
\text { ZHIXING }\end{array}$ & Çin & Teknoloji & $\begin{array}{l}\text { Shaanxi } \\
\text { Mühendislik } \\
\text { Laboratuvarı }\end{array}$ & $12 \mathrm{U}$ & Piller ve Güneş Pilleri & $18 \mathrm{~kg}$ & $\begin{array}{c}200 \mathrm{~km} \times 379 \\
\mathrm{~km}, 40.80^{\circ}\end{array}$ \\
\hline
\end{tabular}

Yapılan literatür çalışmalarında, CubeSat'ların öğrenciler tarafından araştırma projeleri için geliştirdikleri ve uzaya gönderdikleri görülmüştür. Bu kapsamda ABD’nin Stanford ve California Polytechnic üniversiteleri bir proje başlatmıştır. Bu projeye dahil olan kişiler kendi uydularını üreterek uzaya gönderebilmektedir. Üreten kişiye bağlı olarak da uyduların görevleri 
değişmektedir. Ülkemizde de İstanbul Teknik Üniversitesi'nde yürütücülüğünü Prof. Dr. Alim Rüstem Aslan'ın gerçekleştirdiği "Nano Uydu Çalışma Grubu" bulunmaktadır. Bu grupta CubeSat eğitimleri verilerek bu alanda uluslararası yarışmalara katılmışlardır.

Düşük dünya yörüngesinde olan CubeSat'ları daha uzaklara göndermek için yapılan çalışmalar vardır. Bu çalışmaların bir örneği olarak Mayıs 2018'de Mars Cube One (MarCO) uydusu NASA'nın InSight aracı ile gönderilmiştir. Bu uydunun hem kendisi hem de yedeği olmak üzere iki küp uydu uzaya fırlatılarak ayrı ayrı Mars’a yolculuk yapmıştır. Insight’tan verileri Dünya'ya aktarmada başarılı olmuştur.

\subsection{Uzay Nesnelerinin İnterneti (Internet of Space Things/IoST) ve Cubesat}

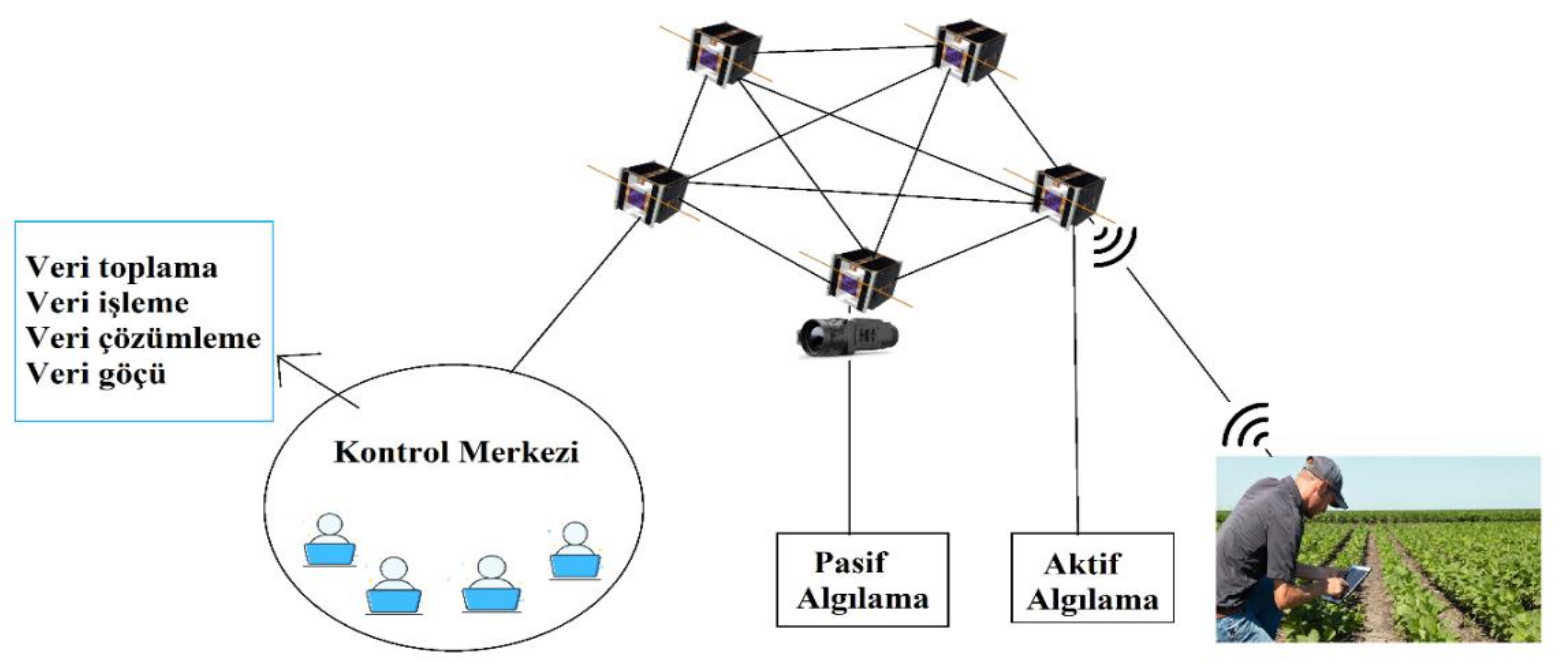

Şekil 5. IoST Genel Yapısı

Ağların ağı olarak tanımladığımız internet, günümüzde her alanda yaygın olarak kullanılmaktadır. İlk olarak 1999 yılında Kevin Ashton "Nesnelerin İnterneti" kavramını ortaya çıkarmıştır. Giderek artan hızı ve teknolojileri ile milyonlarca nesne internete bağlanarak birbirleri ile iletişim kurmaktadır. Bu sayede veri iletişimi yaparak bilgi toplayabilmekte ve bu bilgileri karar vermekte kullanmaktadırlar. Kısaca bir iletişim ağı oluşmaktadır. Bu durum birçok alanda insanların yaşamını da kolaylaştırmaktadır [25].

Nesnelerin internetiyle internetiyle cihazlar arası kablosuz bağlantı yapılması uzay ve uydu alanındaki araştırmalara da katkı sağlamaktadır. Bu katkıların başında tasarım sürecinin kısa olması ve düşük maliyet sunması ile küçük uydu olarak CubeSat'lar gelmektedir. Ayrıca geniş uygulama örnekleri barındırmaktadır. Bunların başında uzaktan algılama uygulamaları gelmektedir [22]. Uydudan verileri verimli şekilde almak ve iletmek için uzayda CubeSat ağları oluşmaktadır. Bu ağlar Şekil 5'te görüldüğü üzere uzay nesnelerinin interneti (IoST) kavramını ortaya çıkarmıştır. CubeSat ağları ile uzayda nesnelerin interneti için bağlantılar oluşturmak daha avantajlıdır. Çünkü bu bağlantılar toprak altyapısına gerek duymazlar. Böylece maliyetin düşürülmesi sağlanır. Aynı zamanda doğal peyzajda korunmuş olur.

Oluşturulan bu ağdan verileri alırken görüntüleme sensörü kullanılarak pasif algılama ve CubeSat ile doğrudan iletişim kurarak aktif bir algılama sağlanmaktadır. Kullanılan görüntüleme sensörleri çoklu çözünürlüklü kameralar olabilmektedir. Böylece kızılötesi görüntüler alınarak arazi izleme olanăğ sunmaktadır. Önceden depreme maruz kalan binalar ve köprülerin izlenmesinde yani doğal afet gibi felaketleri önleme uygulamalarında büyük önem arz etmektedir [26].

Ağdaki CubeSat direkt olarak bir kontrol merkeziyle iletişim kurabilmekte ve kontrol merkezi üzerinden komut gönderebilmektedir. Bu da siber fiziksel sistemin temelini oluşturmaktadır. Günümüzdeki birçok alanda nesnelerin interneti uygulamalarına büyük katkı sağlamaktadır. Örneğin tarım endüstrisinde akıllı tarım teknolojileri ile birlikte üreticiler tarımda toprak, hava ve suyu daha verimli kullanabilmektedir. Verimliliğin sağlanması CubeSat uydularından üreticilere gerçek zamanlı veriler göndererek detaylı bir şekilde analiz ve değerlendirme ile yapılmaktadır. Hava durumunu anlık olarak takip ederek ürünlerini pazarlarda uygun fiyatlarda tüketiciye sunabilmektedir. Şekil 6'da verilen ulaşım endüstrisinin lojistik alanında ise araç takip sistemlerinin gelişmesiyle araçların anlık hareketleri gözlemlenebilmektedir. Bu sayede araçlar verimli bir şekilde kullanılarak taşınan yükün güvenliği arttırılmaktadır. Yine aynı şekilde CubeSat uydularındaki sensörler sayesinde hava koşulları ile ilgili bilgiler aktarılarak ulaşımda çıkabilecek herhangi bir soruna karşı önlem alınmaktadır. 


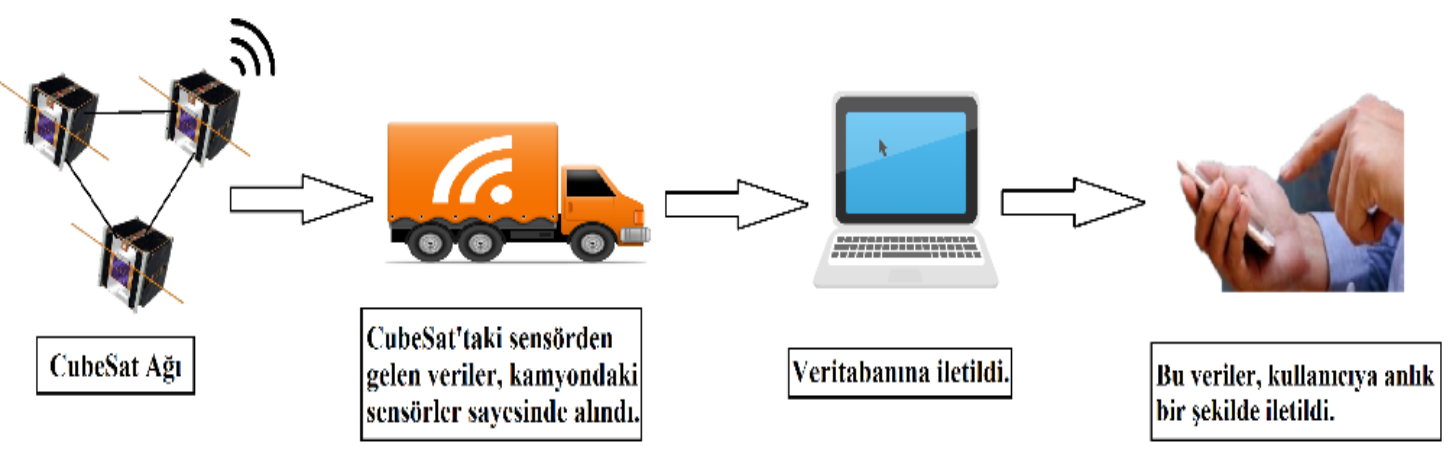

Şekil 6. Lojistik Alanda Araç Takibi

\section{Sonuç}

Bu makalede günümüzde ön planda olan nano uydu çeşidi CubeSat ve uzay gelişmelerine nasıl katkı sağladığı anlatılmıştır. Günümüze kadar üretilmiş olan boyutları ve kütleleri birbirinden farklı CubeSat'lar incelenmiştir. Ayrıca uzayda ağ oluşturarak yer istasyonları ile nasıl iletişime geçtiği hakkında bilgi verilmiştir. Bu ağların uzayda nesnelerin internetindeki (IoST) konumu araştırılarak genel yapısından bahsedilmiştir.

Küçük uydulara uzay ortamında etki eden radyasyonun nasıl oluştuğundan bahsedilmiştir. Uydulara etkiyen radyasyon çeşitleri, yapılan radyasyon testleri ve uydu güç sistemi hakkında genel bilgilendirme yapılmıştır. Elektromanyetik dalgaların azaltılması için ekranlama teorisi geliştirilen bir çalışma incelenmişitr. Bu çalışmada grafen katkılı nanokompozitlerin iyi bir elektromanyetik ekranlama malzemesi olarak üretildiği ortaya konmuştur. Bu nanokompozitler de uygun formlara getirilerek küçük uydular içerisindeki malzemelerde kullanılarak uyduların radyasyondan etkilenmesinin en aza indirilmesi düşünülmektedir.

Üretilen uydularda görüldüğü üzere uydularda kütle ve gücün orantılı olmadığı anlaşılmaktadır. Günümüzde üretimi artan küçük uyduların gelecekte kullanım alanlarının daha fazla olması ve bu sayede küçük kütleli uydularla daha az yer kaplayıp yüksek güç sağlanması beklenmektedir. Uyduların verimli çalışması için yüksek güç düşük kütle istenmesiyle ilgili Türkçe kaynak çok fazla bulunmamaktadır. Buna bağlı olarak da üretilmiş olan uyduların güneş hücrelerinden sağladığı güç değeri ve kütle bilgileriyle uyduların çalışma verimliliği hakkında mukayese yapılmıştır.

\section{Referanslar}

[1] Akkaş, M. A., "Nano iletişim teknolojilerinin biyomedikale katkısı", Sakarya Ünivesitesi Fen Bilimleri Enstitüsü Dergisi, 22(2), 516-528, 2018. DOI: 10.16984/saufenbilder.290340.

[2] Guarducci, F., Coletti M. and Gabriel, S. B., "Design and Testing of a Micro Pulsed Plasma Thruster for CubeSat Application", Presented at the 32nd International Electric Propulsion Conference, Wiesbaden/Germany, IEPC-2011-239.

[3] Ümit, M. E., Baş, M. E., Akyol, İ. E., Uludağ, M. Ş., Ecevit, A. B. ve Aslan, A. R., “Türksat 3USAT Küp Uydusu İçin Elektrik Güç Sistemi Tasarlanması”, IV.Ulusal Havacılık ve Uzay Konferansı, 2012.

[4] Sarı, Ö., "İTÜpSAT1 Uydusunun Entegrasyonu ve Testleri”, İstanbul Teknik Üniversitesi Fen Bilimleri Enstitüsü, Yüksek Lisans Tezi, 2010.

[5] Türkiye Cumhuriyeti Milli Savunma Bakanlığı Hava Kuvvetleri Komutanlığı, "Uydular Ve Yörüngeleri”, 27 Aralık 2019, Available: https://www.hvkk.tsk.tr/Custom/Hvkk/243

[6] Elektronik Haberleşme, "Uydu Yörüngeleri”, 2017, Available: https://www.elektronikhaberlesme.org/uydu-yorungeleri/

[7] THINKTECH, “Küçük Uydular ve Başarı Potansiyelleri”, STM Teknolojik Düşünce Merkezi, Araştırma Raporu, 2019.

[8] Kılıç, G., Örtlek, H. G., ve Saraçoğlu, Ö. G., "Elektromanyetik Radyasyona Karşı Koruyucu Tekstillerin Ekranlama Etkinliği(SE) Ölçüm Yöntemleri”, Erciyes Üniversitesi, The Journal Of Textiles and Engineers, Sayı 72, 2015. 
[9] TAMSAT-Amatör Uydu Teknolojileri Derneği, “Uzay Radyasyonunun Elektronik Devreler Ve Uydu Sistemleri Üzerine Etkileri, Radyasyona Karşı Güçlendirme-1”, 31 Mayıs 2012, Available: https://www.tamsat.org.tr/tr/uzay-radyasyonununelektronik-devreler-ve-uydu-sistemleri-uzerine-etkileri-radyasyona-karsi-guclendirme-1/

[10] Menteş, E., “Kompozit 3U Küp Uyduların Yapısal Analiz ve Tasarımları”, İstanbul Teknik Üniversitesi Fen Bilimleri Enstitüsü, Yüksek Lisans Tezi, 2015.

[11] Türksoy, E. S., Üstündağ, S., Sarıtaş, Ö. ve Saraçoğlu, Ö. G., “Tekstil Malzemelerinin Elektromanyetik Kalkanlama Etkinliği Ölçümünde Yenilikçi Bir Test Aparatı”, Erciyes Üniversitesi, Yüzüncü Yıl Üniversitesi, Araştırma Makalesi, Cilt 22, Say1 99, 2015.

[12] Yılmaz, R., “Elektromanyetik Kalkanlama Özelliği Olan Malzemeler”, Kırklareli Üniversitesi, Elektronic Journal of Vocational Colleges, 2014.

[13] Altun, M., Karteri, İ., Güneş, M. ve Alma, M. H., “Grafen Katkılı Odun-Plastik Nanokompozitlerinin Elektromanyetik Özellikleri ve Elektromanyetik Kalkanlama Etkinliği Karşılaştırmalı Çalışması”, Kahramanmaraş Sütçü İmam Üniversitesi Mühendislik Bilimleri Dergisi. 20(1), 2017. DOI: 10.17780/ksüjes.304082.

[14] Kashi, S., Perumal, V. and Varley, R., "EMI Shielding Effectiveness of Graphene Nanocomposites: Effects of Filler Loading and Thickness", 18th European Conference on Composite Materials Athens, Greece, 2018.

[15] Özkaptan, C. ve Tekinalp, O., “Uzay Uygulamalarında Küçük Uyduların Yeri ve Maliyet Etkenleri”, Tübitak/Orta Doğu Teknik Üniversitesi, Pivolka, Y1l:2, Sayı:6, 2003.

[16] Tübitak Bilim Genç, “Uzaydaki radyasyonu Yeryüzünde Test Edebileceğiz”, 9 Aralık 2019, Available: http://bilimgenc.tubitak.gov.tr/makale/uzaydaki-radyasyonu-yeryuzunde-test-edebilecegiz

[17] eoPortal Directory, "Satellite Missions Database”, 2021, Available: https://eoportal.org/web/eoportal/satellite-missions

[18] Keser, Ö.F., Yenisoy, A. ve İdare, B., "Uydu güç sistemlerindeki güneş hücrelerine yönelik uzay kalifiye mikro lens dizilerinin geliştirilmesi”, Sakarya Ünivesitesi Fen Bilimleri Enstitüsü Dergisi, 2017. DOI: 10.16984/saufenbilder.294872.

[19] IONOLAB, “İyonosfer”, 2011, Available: http://www.ionolab.org/index.php?page=ionosphere

[20] PennState College of Earth and Mineral Sciences, "The Ionospheric Effect", 2020, Available: https://www.eeducation.psu.edu/geog862/node/1715

[21] Carrano, C.S. and Groves, K.M., “Temporal Decorrelation of GPS Satellite Signals due to Multiple Scattering from Ionospheric Irregularities", 23rd International Technical Meeting of the Satellite Division of The Institute of Navigation, Portland, OR, September 21-24, 2010.

[22] Saeed, N., Elzanaty, A., Almorad, H., Dahrouj, H., Al-Naffouri, T.Y. and Alouini, M., "CubeSat Communications: Recent Advances and Future Challenges", 2019. DOI: 10.1109/COMST.2020.2990499.

[23] Haber Ekspres, “Küp Uydular (KÜPSAT)”, 13 Ekim 2016, Available: https://www.haberekspres.com.tr/kup-uydularkupsat-makale,5003.html

[24] Gunter’s Space Page, “CubeSat”, 2020, Available: https://space.skyrocket.de/doc_sat/cubesat.htm

[25] Gündüz, M.Z. and Daş, R., "Nesnelerin İnterneti: Gelişimi, bileşenleri ve uygulama alanları”, Bingöl Üniversitesi, Firat Üniversitesi. 24(2), 327-335, 2018. DOI: 10.5505/pajes.2017.89106.

[26] Aky1ldı, I.F. and Kak, A., “The Internet of Space Things/CubeSats:A ubiquitous cyber-physical system for the connected world", Broadband Wireless Networking Laboratory, School of Electrical and Computer Engineering, Georgia Institute of Technology, Atlanta, GA 30332, United States, 2019. DOI: 10.1016/j.comnet.2018.12.017. 